\title{
Research on key technologies of smart grid supporting smart city
}

\author{
Yang Wang ${ }^{\mathrm{a}}$, Jinyao Lu ${ }^{\mathrm{b}^{*}}$, Yibin Zhang ${ }^{\mathrm{a}}$, Han Huang ${ }^{\mathrm{a}}$ \\ ${ }^{a}$ State Grid Energy Research Institute, Beijing, P.R.China \\ ${ }^{b}$ Beijing Jiaotong University, Beijing, P.R.China
}

\begin{abstract}
Construction of smart city is the fundamental demand of Chinese new urbanization development. Smart grid and smart city fit in the construction concept without previous consultation, which provides an important guarantee for the construction of smart city. Based on the analysis of smart city function requirement, this paper tries to find out the conjunction point of smart city functions and smart grid key technologies, then analysis the key technologies of smart grid for supporting the smart city development, and finally points out the key technologies development trend for better servicing the development of smart city.
\end{abstract}

Keywords: Smart grid, smart city, key technologies

\section{Introduction}

City is an outcome as the economy and culture of the human society developing to a certain stage. Before the Industrial Revolution, European cities were relatively small in size, most of which were formed in a natural manner, with simple functions and infrastructure and poor sanitary conditions. The subsequent Industrial Revolution resulted in a process of urbanization worldwide, during which cities were greatly expended thanks to the emergence of large-scale industries and concentration of rural population to cities. Along with the advent of industrial civilization, technologies and civilizations were continuously applied to urban life and cities became more and more public, given in the premise of productivity development.

Currently, urban development is faced with challenges covering environmental pollution, traffic jam, energy shortage, housing shortage, unemployment and sickness while energy development is experiencing similar pains as large-scale development and utilization of fossil energies have resulted in prominent energy and environment risks, gradually leading the industrial civilization .based on fossil energies to a difficult situation.

In this context, transformation of the social development pattern has become a common understanding of all sectors of the society and "smart" development turns out a new pattern. An Internet-based information technology package that incorporates mobile Internet, cloud computing and big data technology etc. is being widely spread to each corner of our economic and social life (namely, the "Internet + " idea). As a result of the marriage between the need for sustainable urban development and the application of the new generation information technology, smart city, which coincidentally shares a common concept with "Internet+", manages to be a new concept and pattern for global urban development [1].

\footnotetext{
* Manuscript received April 10, 2015; revised August 4, 2015.

Corresponding author. Tel.:+86-10-66603752; E-mail address: wang_yang@ sgeri.sgcc.com.cn

doi: 10.12720/sgce.4.3.199-208
} 


\section{Analysis on Functional Requirements of Smart City}

A smart city that makes the most of inter networks including energy grid, information network, Internet of things and sensor network to integrate all aspects of the city has an intensively inclusive range addressing various fields like energy, infrastructure, people's livelihood, industry and urban management.

Smart energy refers to the realization of sustainable development, efficient transportation and clean utilization of energies through deep integration between modern telecommunication technologies, intelligent control and optimization techniques and the technologies for energy production \& development, storage \& transportation and utilization; Smart infrastructure refers to urban infrastructure than has gone through intelligent transformation. It deals with traffic, water and urban pipe networks and offers more intelligent experiences for the life of urban residents; Smart livelihood refers to intelligent reforms on health, social security, education and community services for urban residents to bring about solutions to issues concerning their vital interests, for example, difficulty in access to medical service, education, housing or employment. Smart industry refers to emerging smart urban industries and upgrades of traditional industries forced by the rapid growth of information technology and Internet of Things to realize efficient, environment friendly, intensified and smart production; Smart governance refers to precise, efficient and timely management. It's a term mainly addressing government administration, urban management and public security and the like [2].

\section{Relationship between Smart Grid and Smart City Development}

\subsection{Key technologies of smart grid}

As something earlier than smart city, smart grid that covers production, transmission, distribution and utilization of electric energy constitutes a modern grid system accommodating safety, environmental protection, efficiency and interaction and does a great job in infrastructure for information and communications, new energy technologies and urban management [3].

Smart grid technologies covers a fairy extensive range, of which the relevant key ones can be classified as power source technology, grid technology, energy consumption technology and information fusion technology [4], as is shown in Fig. 1:

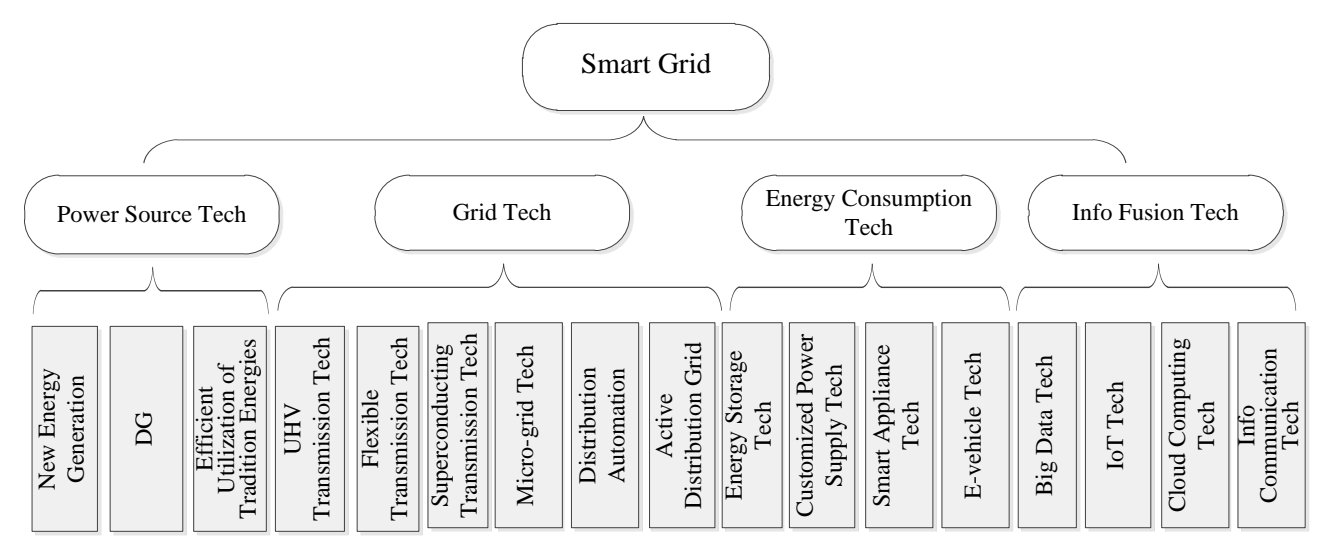

Fig. 1. General view of key technologies of smart grid.

\subsection{Role of key technologies of smart grid in the realization of smart city}

Electric energy is a leading energy to facilitate the running of a city while the power supply system, just like the blood vessel of a city, is closely tied to daily life of urban residents, doomed to be a competent supporter of the relevant functional requirements of a smart city [5].

3.2.1 Smart gird improves urban energy management

The urban smart energy system can be divided into such 3 major parts as smart development, smart storage and transportation, and smart utilization which is shown in Fig. 2. 
Smart development is aimed at sustainable energy development of a smart city, during which process the power source and information fusion technologies can make direct contribution. Integration of clean energies like wind power and PV power and Grid-connected generation technology for small-sized DGs enhance sustainability of urban energy development. More than that, the information fusion technology of smart grid enables better decision-making management by collecting, transmitting and processing data from the generation side [6].

Smart storage \& transportation, as is indicated, mainly refers to efficient and proper storage and transportation of energies. The UHV transmission technology, flexible transmission technology and super-conducting transmission technology of smart grid make it possible for massive development and long-distance transmission of clean energies and help in efficient and clean urban energy transportation. Besides, the information fusion technology of smart grid offers necessary decision-making support and management application for smart storage and transportation.

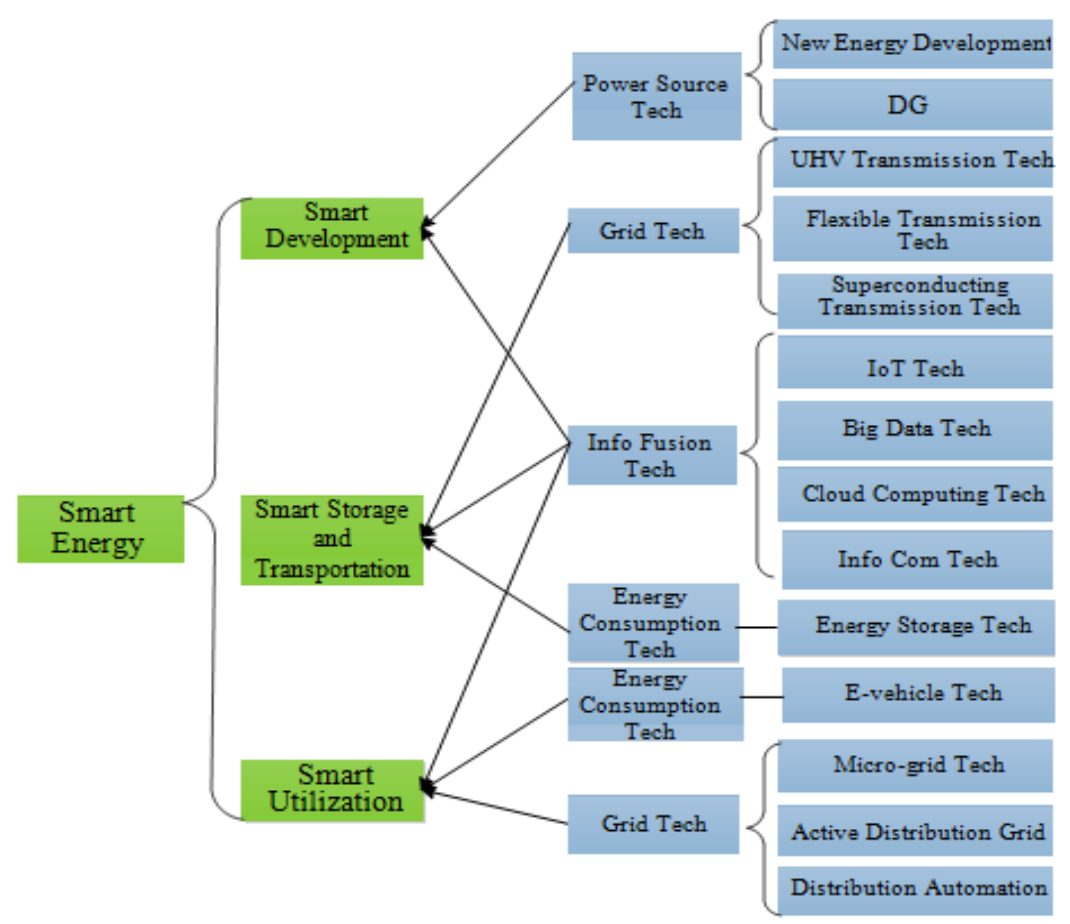

Fig. 2. Key technologies of smart grid support smart energy.

Smart utilization refers to clean and reliable utilization of energies. Backed by its active distribution network technology, distribution automation technology and Micro-grid technology, smart gird manages to present diversified energy consumption modes, regulate regional load of a city, optimize urban load curve, realize consumer interaction, ensure safe and reliable urban energy supply and promote a shift from "passive power consumption" to "smart power consumption". At the same time, E-vehicle technology encourages a pattern transformation from "diversified power consumption" to "electricitydominant consumption". Apart from this, smart grid endows consumers with support for mass information management through its information fusion technology, better serving the consumers.

\subsubsection{Smart gird promote infrastructure building}

Smart Gird Promote Infrastructure Building of Smart City Infrastructure of a smart city covers the information fusion technology of smart grid that applies to water works, pipe network and traffic and Evehicle technology of smart grid is facilitating the development of smart city [7]. Interfacing between relevant functions of smart infrastructure and key technologies of smart grid is shown in Fig.3: 


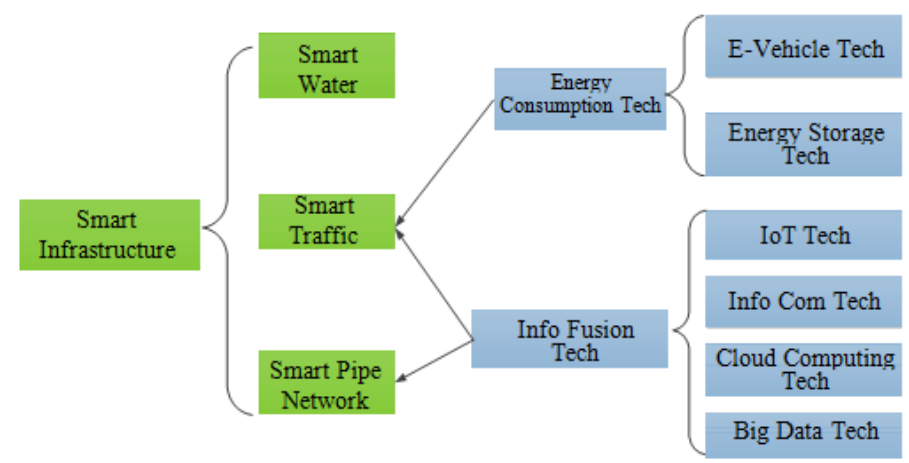

Fig. 3. Key technologies of smart grid support smart infrastructure.

In terms of smart traffic, information fusion technologies can be applied to the integration of bus system, taxi system, monitoring information system for urban expressways for real-time information services of smart traffic. At the same time, perfect E-vehicle charging service network achieves green and convenient travel.

In terms of smart pipe network, Internet of Things propels smart transformation of urban pipe networks for heat supply, oil and gas and telecommunications while such technologies as big data, cloud computing and information communication realize information sharing and resource integration between the pipe networks, enabling precise real-time control and safe and efficient disposal.

Smart water deals with improvement of water resource utilization and real-time monitoring of water environment, in which the supportive role of smart grid is not as obvious.

3.2.3 Smart grid improves residents' life of smart city

Residents' smart experience is the key to the development of smart city, on the entire track of which information resource sharing and guarantee of comfortable and convenient life for the residents shall exist [8]. Interfacing between relevant functions of smart livelihood and the key technologies of smart grid is shown in Fig. 4.

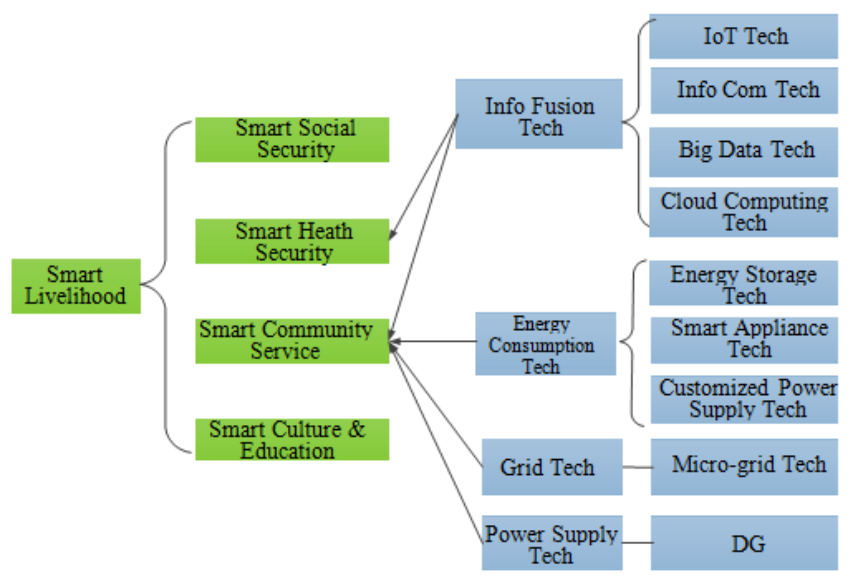

Fig. 4. Key technologies of smart grid support smart livelihood.

In terms of smart health security, the information fusion technology of smart grid plays a supportive role in full sharing of medical resources, scientific and efficient medical process, high-end and smart service approaches and acquisition, storage, transmission, quality control, statistics and utilization of patient information.

In terms of smart community service, smart electric appliance technologies make household security and electric appliance control possible. The information fusion technology provide a two-way interaction 
mode, family services and information services for users. Energy storage technology, distributed generation (DP) technology and Micro-grid technology offer necessary support for reliable power consumption in any smart community. While customized power supply technology improves user satisfaction by meeting personalized needs of power consumers [9].

Smart social security deals with social relief and welfare for residents and smart culture and education with improvement of educational quality and realization of remote education, where smart grid has limited influence.

\subsubsection{Smart gird boosts development of relevant urban industries}

Smart city can full integrate and deep mine massive operating data in a city and realize coordinated operation between resources and key systems, thus inspiring industrial innovations [10]. Interfacing between relevant functions of smart industry and smart grid is shown in Fig. 5.

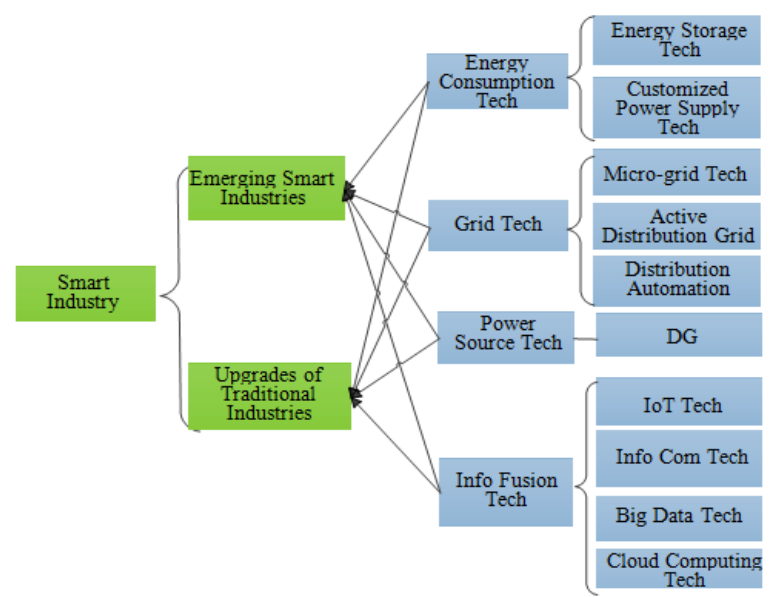

Fig. 5. Key technologies of smart grid support smart industry.

In whether emerging smart industries or upgrading of traditional industries, Micro-grid technology, energy storage technology, DG technology, active distribution technology and distribution automation technology of smart grid improve their production efficiency and reduce losses incurred from power supply interruption. At the same time, customized power supply technology of smart grid satisfies individualized needs of the industrial consumers, ensuring satisfactory power supply. On the other side, information fusion technology helps to break industry barriers to realize information sharing between industrial sectors and making cluster industries real smart ones [11].

\subsubsection{Smart grid enriches municipal management means}

Reasonable, efficient and precise governance of smart city that is essential to promoting harmonious urban development furnishes healthy, steady and harmonious urban development. Interfacing between relevant functions of smart governance and smart grid is shown in Fig.6:

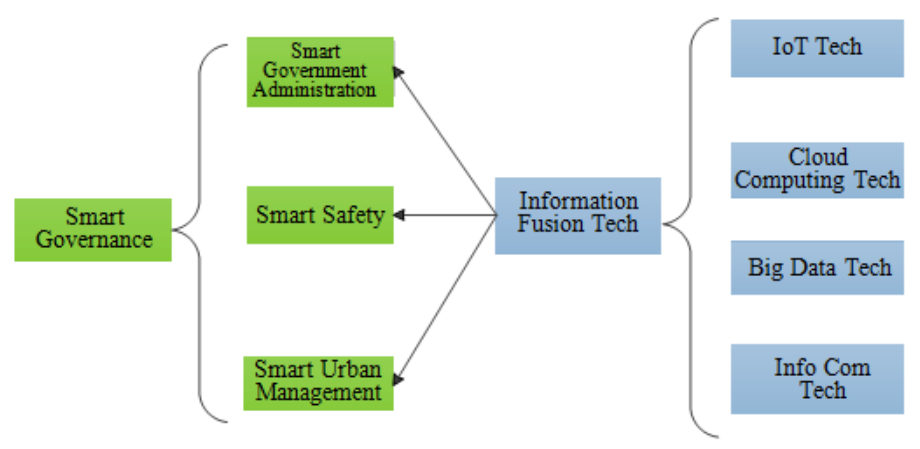

Fig. 6. Key technologies of smart grid support smart governance. 
In terms of smart government administration, information fusion technology of smart grid facilitates the government with online public services and automatically senses and predicts services required by the public. Traditional office automation shall be modified into intelligent office system through artificial intelligence, knowledge management and mobile interconnection, sorting the pending list in the sequence of importance and urgency.

In terms of smart safety, it involves effective early warning against and response to food safety, crime prevention and public disease. Information fusion integrates multiple information sources including current position, population and geographical space to establish model prediction for higher prevention capability. At the same time, trans-department and multi-function collaboration can be promoted and trans-department information can be integrated for sharing to ensure rapid, resolute and effective emergency management.

In smart urban management, information fusion technology helps build a management pattern where basic service, GIS share service and uniform video monitoring act as application supporters and digital urban management, emergency command and team management as main functions, thus achieving the transformation from traditional urban management to the smart.

\section{Research on the Development Trend of Key Technologies of Smart Grid to Support Smart City}

Analysis on the development relationship between smart grid technologies and smart city reveals that smart grid supports the major functions of smart city from various aspects to promote smart life, learning and work. Thus, higher and more urgent demands for innovation of smart grid technologies in place in the building of an "intelligent, green, intensified and livable" smart city, which in return drives continuous breakthroughs and innovations in energy power generation technologies [12].

\subsection{Power source technology}

Power source technology constitutes an important foundation for the development of smart grid and promotion of clean substitution. As is learnt in Section III, power source technology braces smart energy and the supportive functions of clean energy generation technology and DG technology are obviously observed.

\subsubsection{Clean energy generation technology}

Currently, among those widely used are wind generation and PV generation technologies.

(1) As wind is an intermittent and fluctuating power source, there is a need carry out researches on the wind resource evaluation and prediction technologies, wind generation equipment manufacturing technologies and control technology for wind power integration to improve controllability of wind power and ensure safe and stable operation of the grid after large-scale integration.

(2) Battery is a major device in PV generation. With the ever increasing conversion rate of the crystalline silicon PV battery, generation cost is continuously decreasing, enhancing its competitiveness. Currently, the crystalline silicon battery basically meets the generation demand, which, however, might hinder the massive PV generation development due to its large volume, high cost and low efficiency. Thin-film battery with high efficiency, low cost and sliced feature might be a right track.

\subsubsection{DG technology}

Currently, electricity generated by most distributed sources of new energies cannot meet the requirement of gird whether in frequency or voltage level. Besides, excessive access of distributed sources may result in changes to voltage pattern and short-circuit current of the existing grid, affecting electricity quality, changing the system flow direction and eventually affecting protective action. Relay protection and optimized energy management technology will be the directions for future development of distributed power source [13].

\subsection{Grid technologies}

Grid technologies mainly offer support for aspects like smart energy, smart industry and smart livelihood, distribution automation, active distribution grid and Micro-grid technologies will be directly 
applied to smart city while UHV transmission technology, flexible transmission technology and superconducting transmission technology with large capacity, long distance and high voltage level will better facilitating development of smart city [14].

\subsubsection{UHV transmission technology}

(1) In terms of transmission technology: it satisfies such objectives as long distance, large capacity and economical corridor while complex technology integrating compactness, multi-loop line and flexible AC shall be developed. Besides, external insulation design for lines in high altitude regions is a turning point in the development of transmission technology, which requires intensive R\&D to try our proper materials and insulation coordination.

(2) In terms of transformation equipment: Priorities shall be given to the development of large capacity transformer, high-end converter transformer, heavy current SF6circuit breaker, modular site assembly technology for large transmission and transformation equipment and intelligent transformation equipment with smaller size and loss to satisfy the demands for large capacity transmission, land conservation and intelligence.

\subsubsection{Flexible transmission technology}

In terms of flexible transmission technology, such issues as reliability, transmitting capacity, cost and electromagnetic interference remain with electric and electronic devices as the core of such a technology. In this light, more efforts are expected to develop more cost-effective devices and high performance devices with higher switching power in future.

\subsubsection{Superconducting transmission technology}

It is predicted that by 2030 , the superconducting technology is obviously limited in the technological and economical regards with limited R\&D and application progress, insufficient to influence the existing grid pattern. In the long run, with breakthroughs in high-temperature superconducting cable related technology and reduction of its economic cost, its advantages will become more and more apparent, making it possible to gradually replace part of the underground cable and transmission line and become the key next generation technology. Possibilities do exist for superconducting cable to gradually substitute UHV or large capacity cable with technological advancement and reduction in cost in the future. This might be a slow process, far longer than the design service life of the transmission and transformation equipment now in production.

\subsubsection{Micro-grid technology}

The application range of Micro-grid technology will be continuously expanded as the development of smart city, before which breakthrough in the following aspects shall be in place.

(1) Micro-grid operation control and protection technology;

(2) Micro-gird energy quality monitoring and management technology;

(3) Micro-grid optimized energy management technology.

\subsubsection{Active distribution grid}

Active distribution grid, as a trend for the development of future smart grid, has an obvious promotion effect on smart city. Currently, research on active distribution is under way in China, which covers R\&D for key technologies of traction battery, Micro-grid converter, E-vehicle recharging station, active distribution grid energy scheduling and energy quality control with an aim to promote the development of E-vehicle and Micro-grid technologies, better serving smart city. Active distribution grid that is gifted with high potential deserves consistent researches.

\subsubsection{Distribution automation}

Development of distribution automation satisfies and ensures power supply quality and meets the requirements of high-tech equipment and intelligent household appliances. Currently, certain achievements have been with the distribution automation technology. In the future, it shall be enabled to accommodate the massive accesses of distributed power sources and DFACTS, satisfy the monitoring demand of bi-directional power flow distribution grid and support the plug and play of monitoring devices and software [15]. 


\subsection{Energy use technology}

Energy use technology supports smart energy, infrastructure, livelihood and industry, etc. It is the key and emphasis of smart grid to support the development of smart city. Meanwhile, the innovation and development of energy use technology is an important technological basis for large-scale clean use of energy.

\subsubsection{Electric vehicle technology}

Electric vehicle technology plays an evident role in supporting the development of smart city. Research in electric motor and control technology and charging and discharging equipment technology has caught up with the development of smart city. At present, however, electric vehicles face such major problems as short range, slow charging, etc, whose usage performance needs to be improved [16].

\subsubsection{Energy use technology}

At present, pumped-storage technology is the most mature one among all storage technologies, while other storage technologies are still in the process of test and demo or even initial research. In spite of a bottleneck battery storage has confronted with due to high-performance storage materials, it boasts tremendous development potential and application prospect and it is expected to herald industrialized development. However, we need to further improve energy density and reduce costs in developing the storage technologies applied to distributed storage equipment such as superconductivity, flywheel and super capacitor [17].

\subsubsection{Customized electricity technology}

Normal electricity use among urban residents is disturbed by various problems, e.g. voltage jump, voltage dip and instant blackout, etc in electricity distribution system. Hence, we need to develop such technologies as series voltage regulation, shunt compensation, series-parallel mixed applications, uninterruptible power supply (UPS), high-speed power switch, fast fault-clearing and storage system, etc to satisfy the customized electricity required by users.

\subsubsection{Smart electric appliance technology}

Smart electric appliances are the products of currently developing information technology merging into traditional electric appliances, not only improving the living quality of urban residents, but also enabling each electric appliance to work optimally. However, the development potential of smart electric appliance as electronic equipment is restricted by its high cost. Hence, we need to further the study gradually according to technological development of the Internet of Things.

\subsubsection{Information integration technology}

Information integration technology supports the five functions of smart city. The establishment of smart city is most closely connected to such technologies of smart grid as the Internet of Things, big data, cloud computing and information communications. Hence, we need to highlight the research in information integration technology when developing smart grid so as to serve smart city better [18].

\subsubsection{Technology of the internet of things}

(1) Information perception technology focuses on UHF, microwave and RFID technologies applicable to life cycle management of electricity assets, distributed, intelligentized, multi-parameter, field-using passive FOS and WSN technology exclusively used for electricity, and electric integration technology between sensors and primary electric equipment.

(2) Information transmission technology focuses on the application of short-distance wireless ad hoc network technology to condition monitoring, advanced metering and interaction between grid and users and LDO, lightweight, tailor able wireless sensors network protocol stack based on IPv6 and mobile IP technology supporting double stacks of IPv4 and IPv6.

(3) Information processing technology focuses on mass information network/virtual storage, data classification mechanism under mixed conditions, distributed file system, real-time database technologies, smart analysis theory and methodology of multi-dimension image and video, advanced data coupling and layered disjunction strategies facing targets and business.

(4)Information security technology will focus on studying the perception-network-application security framework of Electric Internet of Things, establishing a safety guarantee system and forming a 
"manageable, controllable, reliable and dependable" security framework of Electric Internet of Things in the future [19].

\subsubsection{Big data and cloud computing technology}

As an important strategic property, big data have penetrated into all aspects of smart grid and thus boost further development of the industry. Cloud computing technology is a supporting technology of such technologies as the Internet of Things and big data. Since 2013, big data technology has been integrated closed with cloud computing technology. And their connection is expected to be closer in future.

\subsubsection{Information communications technology}

Communications and information technology will be integrated with power industry in depth. Information service products based on service will improve the interaction between grid and users considerably. Expert service software will provide power enterprises with information processing service. The cost of informationized communications will be reduced tremendously; brand-new communications technologies (e.g. quantum communication) will be applied to the electricity system, and new encryption technologies like quantum encryption will ensure secure transmission of electricity information.

\section{Conclusion}

Key technologies of smart grid support the development of smart city in the aspects of smart energy, infrastructure, livelihood, industry and governance. By analyzing the integration between smart city functions and key technologies of smart grid as well as the development trend of the key technologies in smart grid, the paper is dedicated to the conclusion as follows:

1) Although smart grid fully supports smart city, some technologies of smart grid are connected to smart city more closely. Smart grid technology ranges widely and covers power generation, transmission, transformation, distribution, utilization and information processing. Distributed generation, micro-grid, active distribution network, automatized distribution, energy storage, customized electricity, smart electric appliance, electric vehicle, the Internet of Things, big data, cloud computing, information communications technologies will play a more evident role in the process of integration with smart city.

2) The establishment of smart city is still in the process of start-up, and current technologies of smart grid can satisfy the requirements of smart city establishment. Smart grid developed earlier than smart city. Ultra-high voltage transmission, clean energy generation, distributed generation, automatized distribution technologies have been mature, which can satisfy the current requirements of smart city development.

3) Smart grid will make breakthrough in new technological fields and further supports the development of smart city in the future. The development objectives of "intelligence, green, livability and economy" of smart city in the future propose higher requirements for smart grid. To support the development of smart city better, we should increase investment and enhance R \& D in superconducting transmission, large-scale energy storage, big data and cloud computing technologies when developing smart grid.

\section{References}

[1] Aliresearch. (2015). AliresearchInternet+report. [Online]. Available: http://www.aliresearch.com

[2] Shi JAQ. Research on several key technical problems in realization of smart grid. Power System Protection and Control, 2009; 37(19):1-4.

[3] Zhang HR. An overview of key technologies on smart grid. Mechanical Engineering \& Automation, 2013; (2):212-214.

[4] Lin YF, Zhong J, Wu FL. Discussion on smart grid supporting technologies. Power System Technology, 2009; 22(12);8-14.

[5] He DY. Thinking on problems and achievements in smart-grid development. Electric Power, 2012; 45(8):37-40.

[6] Zhao JX, An XM. Strong and smart grid supports the construction of wisdom city in Shanxi. Shanxi Electric Power, 2013, (3):37-39.

[7] Yu YY, Zhou CH. International comparison of construction mode on intelligent infrastructure. National Science Theory and Subject Construction and Science and Technology between the Joint Annual Meeting Proceedings in 2012, 2012. 
[8] Gu DD, Qiao W. Study on the construction of evaluation index system of China's Smart City. Future and Development, 2012; (10).

[9] Zhang XY, Yuan ZP. Convergence developmen of intelligent city and industry in Guangzhou. Science \&Technology Progress and Policy, 2013; (12).

[10] Wang JJ. Urban "intelligent governance": the integration of information technology, the functions of the government and social governance mechanisms - with the examples of Hangzhou uptown urban governance innovation. Guan Cha Yu Si Kao, 2014; (7):50-54.

[11] Zeng M, Li HL, Xue S, et al. Key technologies of future smart grid construction based on power system security: a view of blackout in India and experience and enlightment to power industry in China. Proceedings of the CSEE, 2012; 32(25):175-181.

[12] Wang ML, Zhang YJ, Lin JX. A review on distributed generation development. Electrotechnical Application, 2011 ; (9):36-39.

[13] Ji Y, Ai Q, Xie D. Research on co-development trend of distributed generation and smart grid. Power System Technology, 2010; 32(12):15-23.

[14] Wu HX. Flexible exchange and transmission technology in intelligent power grid the current status and prospect. Friends of Science Amateurs, 2011; (33).

[15] Tang XJ. The application of power transmission and transformation technology in the smart grid. Low Carbon World, 2014; (1).

[16] Xue F, Lei XZ, Zhang YB, et al. A brand-new approach of connecting electrical vehicles with smart grid from vehicle-to-grid mode to battery-to-grid mode. Power System Technology, 2012; 36(2):29-34.

[17] Hua GH, He WG, Zhao DW. Role of energy storage technologies in the construction of strong smart grid. Distribution \& Utilization, 2010; 27(4):22-29.

[18] Bao F. The application of new information technology in smart grid. Electronic Technology \& Software Engineering, 2013; (13).

[19] Wang JY. Information technology of supporting smart grid. Electric Power IT, 2010; 8(4):1-3. 